\title{
ENFERMAGEM E FAMÍLIAS DE CRIANÇAS COM SÍNDROME NEFRÓTICA: NOVOS ELEMENTOS E HORIZONTES PARA O CUIDADO ${ }^{1}$ NURSING AND FAMILIES OF CHILDREN WITH NEPHROTIC SYNDROME: NEW ELEMENTS AND HORIZONS TO TAKE CARE ENFERMERÍA Y FAMILIAS DE NIÑOS CON SÍNDROME NEFRÓTICO: NUEVOS ELEMENTOS Y HORIZONTES PARA EL CUIDADO
}

\author{
Rosa Lúcia Rocha Ribeiro², Semiramis Melani Melo Rocha
}

\begin{abstract}
${ }^{1}$ Este artigo faz parte de uma pesquisa maior que se constituiu na tese de mesmo título, defendida pela primeira autora em 2005, na Escola de Enfermagem de Ribeirão Preto (EERP) da Universidade de São Paulo (USP). Obteve apoio da Coordenação de Aperfeiçoamento de Pessoal de Nível Superior (CAPES) e do Conselho Nacional de Desenvolvimento Científico e Tecnológico (CNPq).

${ }^{2}$ Enfermeira. Doutora em Enfermagem em Saúde Pública pela EERP/USP. Professora Adjunta da Faculdade de Enfermagem (FAEN) da Universidade Federal de Mato Grosso (UFMT).

${ }^{3}$ Professora Titular Aposentada da EERP/USP. Pesquisadora do CNPq e da Fundação de Amparo à Pesquisa do Estado de São Paulo (FAPESP). Professora Catedrática Visitante na Universidade de Aveiro, Portugal. Professora Colaboradora na Universidade de Franca, SP.
\end{abstract}

PALAVRAS-CHAVE: Enfermagem pediátrica. Nefrologia. Criança. Doença crônica. Enfermagem familiar.

KEYWORDS: Pediatric nursing.Nephrology.Child.Chronic disease. Family nursing.

PALABRAS CLAVE: Enfermería pediátrica. Nefrología. Niño. Enfermedad crónica. Enfermería de la familia.
RESUMO: A condição crônica tem sido um tema de relevância para a reflexão do processo de viver humano. O artigo apresenta a síntese de uma pesquisa cujo objetivo foi compreender o cuidado às crianças com Síndrome Nefrótica, identificando novos elementos contextuais e horizontes para reconstruir o cuidado de enfermagem, tendo como foco a família. Trata-se de um estudo qualitativo apoiado na hermenêutica, fundamentada em Gadamer e Ricouer, realizado em 2004, com famílias de crianças do Ambulatório de Nefrologia Pediátrica do Hospital Universitário Júlio Müller, em Cuiabá, totalizando 42 pessoas. Na discussão são apresentados: síntese das famílias, na qual elas são mostradas por meio das suas biografias, projetos, personagens e contexto; a trajetória da doença da criança na família e o cuidado da criança com Síndrome Nefrótica, no qual revelam-se os horizontes dos cuidadores, familiares e profissionais de saúde, e o cuidado possível a partir dos arranjos da família e limites da equipe. Conclui-se que o diálogo é a primeira condição para a compreensão e para o cuidado.

ABSTRACT: Chronic conditions have been extremely relevant issues to consider when reflecting about the human living process. The purpose of this study was to understand how to care for children with Nephrotic Syndrome in nursing practice, focusing on the family. Thefamilies' narratives were interpreted in this qualitative study based on the hermeneutic approach of Gadamer and Ricouer. The participants of this study were the families of children and adolescents with Nephrotic Syndrome who in 2004 attended the Pediatric Nephrology Service at the Júlio Müller University Hospital, in Cuiabá, Brazil. The discussions were grouped into three categories: Synthesis of the families, presented by means of their biographies, projects, personalities, and contexts; The trajectory of the child's condition in the family; and the Care for the nephrotic child. These aspects reveal the points of view of the caregivers, family members and health professionals, as well as the care possibilities in view of the family arrangements and team limitations. Our conclusion is that dialogue is the first condition to understanding and to offering care.

RESUMEN: La condición crónica ha sido un tema de importancia extrema para la reflexión del proceso de vivir humano. En el artículo se presenta la síntesis de una investigación realizada con la finalidad de comprender cómo los niños con Síndrome Nefrótico son cuidados, buscando identificar nuevos elementos y horizontes para reconstruir el cuidado de enfermería, teniendo como foco la familia. Para la presente investigación, se realizó un estudio cualitativo que utilizó como referente teórico metodológico, la hermenéutica basada en Gadamer y Ricouer. De la investigación realizada en 2004, participaron 42 personas pertenecientes a las familias de niños y adolescentes con Síndrome Nefrótico, usuarias del Servicio de Nefrología Pediátrica del Hospital Universitario Júlio Müller, en Cuiabá, Brasil. En la discusión son presentadas: una síntesis de las familias, sus proyectos, personajes y contexto; la trayectoria de la enfermedad del niño en la familia, y el cuidado del niño nefrótico en la familia. Se muestran también los horizontes de los cuidadores, familiares y profesionales de salud, y el cuidado posible a partir de los arreglos de la familia. Se puede concluir que el diálogo es la primera condición para la comprensión y también para el cuidado.
Endereço: Rosa Lúcia Rocha Ribeiro

Av. Rubens de Mendonça, 3000, Ap. 201-B

78.050-000 - Bosque da Saúde, Cuiabá, MT.

E-mail: rosalucia@gmail.com
Artigo original: Pesquisa

Recebido em: 15 de agosto de 2006. Aprovação final: 05 de janeiro de 2006. 


\section{INTRODUÇÃO}

A condição crônica tem sido um tema de extrema relevância para a reflexão do processo de viver humano. Define-se condição crônica na infância como aquela que interfere no funcionamento do corpo da criança em longo prazo, requer assistência e seguimento por profissionais de saúde, limita as atividades diárias, causa repercussões no seu processo de crescimento e desenvolvimento afetando o cotidiano de todos os membros da família. ${ }^{1}$

Como na maioria das doenças crônicas na infância, a Síndrome Nefrótica (SN) altera as vidas das crianças em todos os níveis, além de lhes impor a possibilidade de abreviar a vida ou limitar atividades da vida normal.

A SN caracteriza-se por aumento grave e prolongado de permeabilidade glomerular às proteínas. $\mathrm{O}$ principal achadoéaproteinúria associada a hipoalbuminemia e edema. Pode ocorrer em qualquer idade, mas é mais comum em crianças do sexo masculino entre as idades de 1,5 a 4 anos. A doença de lesões mínimas é o tipo mais freqüente. Considera-se que a proteinúria ocorra através do desarranjo funcional de dois mecanismos: a barreira tamanho-seletiva deixa escapar grandes moléculas protéicas, e a barreira carga-seletiva deixa de reter proteínas de menor peso molecular. ${ }^{2}$

Geralmente o edema focal é a razão da consulta ao médico que inclui queixas variadas. Em crianças é muito comuma queixade dor abdominal em virtude do edema de mesentério. Mais freqüentemente, o edema é móvel, detectado nas pálpebras pela manhã e nos tornozelos após a deambulação. Oacúmulo de líquidos ocorre devido à relação entre a pressão hidrostática e oncótica nos capilares e interstício, devido a fatores sistêmicos que faz aumentar a fração de reabsorção de sódio, como o mecanismo renina-angiotensina-aldosterona. A oligúria ou mesmo insuficiência renal aguda podem se desenvolver devido à hipovolemia e perfusão diminuída. Ocasionalmente, ocorre insuficiência renal aguda oligúrica. Pode haver hipotensão ortostática ou mesmo choque em crianças. Em razão disso, a conduta adequada é o estímulo a ingesta hídrica, além de um controle rigoroso da pressão arterial. ${ }^{2}$

$\mathrm{NaSN}$ prolongada podem ocorrer deficiências nutricionais, incluindo desnutrição protéica ekwashiorkor, cabelose unhas quebradiços, alopecia, crescimento retardado, desmineralização óssea, glicosúria, hiperaminoacidúria de diversos tipos, depleção de potássio, miopatia, redução do nível sérico de cálcio, tetania e hipometabolismo. A perda da massa muscular pode es- tar mascarada pelo edema. Pode haver peritonite espontânea e infecções oportunistas. A maior incidência de infecções pareceserdevidoà perda deimunoglobulinas. As alterações da coagulação, juntamente com atividade fibrinolítica diminuída ehipovolemia episódica, levam a um risco de trombose da veia renal. ${ }^{2}$

A SN tem um prognóstico favorável desde que bem conduzido o tratamento. O uso de diuréticos para a redução do edema tem sido contestado pelos efeitos danosos aos glomérulos e parece ter relação com o curso arrastado de muitos casos da doença. Os casos de doença de lesões mínimas que respondem bem à imunossupressão com corticosteróides têm o melhor prognóstico.Écomum ocorrer recidivas. Otratamento da SN é dirigido para o processo patogênico de base. A biópsia renaldetermina o melhor tratamento. A resposta ao tratamento é indicada pela cessação da proteinúria e diurese na presença de edema. Cerca de $90 \%$ das crianças respondem a terapia inicial com prednisona, mas $75 \%$ destas apresentam recidivas. ${ }^{2}$ Para os pacientes que não respondem aos corticosteróides e apresentam recidivas freqüentes, utiliza-se a combinação de prednisona com um agente citotóxico como a ciclofosfamida ou o clorambucil. Uma abordagem alternativa é o uso de ciclosporina. Mais recentemente tem sido introduzido o micofenolato mofetil para crianças que já usaram os esquemas clássicos de tratamento sem resolução. ${ }^{3}$

A dieta deve ser normal em proteínas e potássio e baixa em colesterolesódio. Tem sido indicadaaingestão deóleode peixe(Omega3) que, porconterácidosgraxos poliinsaturados, reduz a concentração de triglicerídeos. Indica-se também o uso de suplemento vitamínico.

Os efeitos do uso prolongado dos corticosteróides (cusbing) tais como a imunossupressão, hirsutismo, aumento do peso, aparecimento de estrias, hiperatividade, irritabilidadee aumentodoapetitedevemserinformados para as famílias, também devem ser orientadas quanto à imunização. As vacinações devem ser proteladas para após o tratamento com corticosteróides. No entanto, a vacina anti-pneumocócica pode ser administrada. Seu uso justifica-se para a prevenção de doenças respiratórias, muitocomunsnascriançascom $\mathrm{SN}$, quefreqüentemente levam a recidivas da proteinúria. ${ }^{3}$

Infusões de albumina são usadas apenas em casos muito bem indicados, que apresentam evidências clínicas de depleção profunda do volume intravascular.

Dados da Sociedade Brasileira de Nefrologia mostram que existiam 54.523 pacientes em diálise no Brasil em 2002. As três maiores causas de Insuficiência Renal Crônica Terminal (IRCT) no Brasil 
são: doenças glomerulares (27,5\%), nefroesclerose hipertensiva $(16,8 \%)$ e nefropatia diabética $(8 \%)$. As causas adicionais são: nefrite intersticial (4\%), doenças policística renal (3\%), nefrose lúpica $(1,3 \%)$ e outras causas $(3,4 \%)$. Em $36 \%$ dos casos a etiologia não é precisa. A mortalidade anual entre pacientes em diálise crônica está em torno de $17 \%{ }^{4}$

Mesmo sendo reconhecida como a principal causa de IRCT, no Brasil há poucos estudos epidemiológicos sobre doenças glomerulares. Não há estudos de incidência e prevalência de glomerulopatias na população brasileira, sendo que os estudos sobre doenças crônicas não transmissíveis têm sido limitados às doenças do aparelho circulatório, diabetes, neoplasias e às causas externas..$^{5-6}$ Além disso, tem sido difícil precisar o número exato das doenças glomerulares uma vez que os registros no Brasil se fazem a partir das internações e da Classificação Internacional de Doenças, $10^{\mathrm{a}}$ versão (CID-10). Isto implica na sua pouca visibilidade e, por consegüinte, na não valorização das doenças glomerulares nas políticas de saúde.

A discussão da doença crônica na infância tem sido associada mais freqüentemente às doenças como o câncer, diabetes, fibrose cística, problemas neurológicos e doenças respiratórias como a asma. Não existem publicações de enfermagem que tratem das doenças renais crônicas e doenças glomerulares na infância, mais especificamente a SN, tanto nas fontes nacionais como estrangeiras. Contudo, existem muitos trabalhos da enfermagem e também da nefrologia pediátrica voltados para a discussão da insuficiência renal crônica e cuidados com os procedimentos de diálise. Em alguns poucos estudos brasileiros relacionados à $\mathrm{SN}$, de abordagem qualitativa, o medo aparece como um fator importante na vida de crianças doentes e de suas famílias. ${ }^{7,8} \mathrm{O}$ desconhecimento da doença e de sua etiologia costuma levar os pais a buscarem explicações existenciais para a sua ocorrência. ${ }^{8}$

As reações da família variam de acordo com a severidade da condição da criança, das demandas no seu manejo e da quantidade de suporte disponível. No caso da SN existem graus diferenciados de severidade que se relacionam à fase da doença, ao seu tratamento e também ao seu prognóstico, demandando um manejo habilidoso da enfermeira junto à família, seja nos aspectos técnicos ou de interação.

Ao longo das últimas quatro décadas passamos por distintos discursos e práticas de cuidado às pessoas com doenças crônicas no Brasil. Primeiramente havia a preocupação em conhecer as doenças, encontrar medicamentos capazes de controlá-las ou aliviar os sintomas e tratar as complicações. Depois passamos pela fase de "educar" as pessoas "oferecendo as informações necessárias", na expectativa da adesão ao tratamento. Em seguida, a preocupação passou a ser a prevenção de doenças crônicas com campanhas para orientar as pessoas a evitar ou retardar algumas doenças, em especial as mais freqüentes. Vivemos um novo momento que é decorrente de uma maior compreensão do que é o processo de viver com a doença crônica. Atualmente, tem-se investido numa educação em saúde na qual "[...] a pessoa com doença crônica e sua família sejam protagonistas do processo educativo, de modo a encontrarem maneiras saudáveis de conviver com a doença, sem negarem a extensão que a mesma pode provocar em suas vidas. Neste contexto, o profissional de saúde precisa colocar-se como um parceiro na construção de um viver saudável. Seu papel inclui o compartilhar saberes, a busca constante por mais compreensão sobre o que é viver com uma doença crônica, a não imposição de cuidados e tratamentos, encontrando alternativas que ajudem essas pessoas a terem uma vida com mais qualidade. A tônica do cuidado passa a ser a flexibilidade, a compreensão, o estar disponível e a horizontalidade do diálogo". 9:11

Os pesquisadores, em especial enfermeiros, têm se mostrado cada vez mais interessados e voltando seus olhares para métodos de assistência a famílias que convivem com crianças com doenças crônicas. A maioria dos artigos que discute a "doença crônica e família” descreve ou conceitua as respostas das famílias às doenças. Há vários estudos que buscam compreender a vida familiar no contexto da doença. ${ }^{10}$ Outrotemaabordado procura compreender comocrianças e adolescentes com doença crônica têm seu cotidiano modificado pelas freqüentes hospitalizações, pelos limites ditados pela doençaetratamento, ocasionando mudanças, especialmente no processo de escolarização. ${ }^{11}$

\section{JUSTIFICATIVA E OBJETIVOS}

Ajustando nosso olhar para o horizonte do cuidado de enfermagem às crianças com $\mathrm{SN}$, apresentamos a pergunta que norteou nossa pesquisa: as crianças com SN estão sendo cuidadas?

Para responder a esta questão, nos apoiamos nos fundamentos teórico-metodológicos da filosofia hermenêutica. ${ }^{12-14}$ 

cativas:

Assim, o estudo apresenta as seguintes justifi-

- a cronicidade, característica da SN, aponta para questões que reclamam por um cuidado no seu sentido mais amplo;

- os elementos presentes no contexto das famílias que vivem a doença crônica mostram que não há como cuidar delas aplicando apenas os conhecimentos da ciência tradicional e as técnicas terapêuticas limitadas;

- a prática e os conhecimentos produzidos, em especial na área da enfermagem, revelam a impossibilidade de aplicar um cuidado adequado para crianças com uma condição crônica sem incluir a família no seu plano de cuidados;

- para as crianças crônicas serem adequadamentecuidadas, é preciso conhecer as famílias e o seu cotidiano, buscandoidentificarelementoscontextuais relevantes para o cuidado.

Por essas questões, o estudo teve como objetivo compreender como as crianças com SN estão sendo cuidadas, buscando, por meio da hermenêutica, identificar novos elementos contextuais e horizontes para reconstruir o cuidado de enfermagem, tendo como foco a família.

\section{METODOLOGIA}

Trata-se de um estudo qualitativo com apoio teórico-metodológico na hermenêutica, fundamentada em Gadamer ${ }^{12}$ e Ricouer ${ }^{13}$.

A hermenêutica é considerada como a disciplina que se ocupa da arte de compreender textos podendo estesser biografias, narrativas, entrevistas, documentos, livros, artigos, dentre outros. A origem da palavra vem da mitologia grega, segundo a qual Hermes transmitia as mensagens dos deuses aos mortais, não apenas as anunciando textualmente, mas as interpretando com palavras inteligíveis e significativas.

A hermenêutica não pode ser considerada um método, mas uma atitude filosófica para o "diálogo científico". A hermenêutica convida o outro a enxergar a dimensão racional de nossa existência humana como um diálogo sempre em curso, sendo este diálogo movido por valores, por possibilidades objetivas de concretizar esses valores e por modos sempre intersubjetivamente construídos de conceber esses valores e apreender suas possibilidades concretas de realização. A hermenêutica não propõe nenhuma metodologia para este diálogo científico. Senão já não seria diálogo, mas um monólogo ${ }^{14}$. O que a hermenêutica se propõe é uma certa compreensão das condições e possibilidades desse diálogo e, conseqüentemente, das suas potencialidades. E este diálogo, para se efetivar, depende de quem fala, para quem fala, onde fala, quando fala e para quê fala, ou seja, o sujeito datado e localizado ${ }^{14}$.

Assim, "construímos" a metodologia do nosso estudo e não "aplicamos" uma metodologia pré-definida. Para isso, quanto mais tivéssemos conhecimento sobre as reflexões trazidas pela hermenêutica filosófica, ou dialética, mais condições teríamos para identificar nossos próprios valores e interesses práticos em relação ao nosso objeto de estudo e melhores condições teríamos para balizar uma boa conversa sobre ele com nossos pares. Além disso, quanto mais elementos tivéssemos para compreender a verdade objetiva deste objeto (isto é, aspectos de sua existência que estivessem relacionados ao interesse de nossa investigação e que fossem apreensíveis por nossos pares como uma realidade evidente), mais chances teríamos de realizar uma conversa produtiva. Precisávamos então de uma teoria, ou, mais provavelmente, de várias teorias, que nos permitissem esse compartilhamento intersubjetivo da realidade de nosso objeto-nem que fosse para recriá-lo, adaptá-lo ou reconstruí-lo. Contudo, não podíamos nosesquecerque estávamos imersos num diálogo, e foi no curso desse diálogo que nosso discurso se conformou.

A pesquisa foi realizada no período janeiro a novembro de 2004 com nove famílias de crianças usuárias do Ambulatório de Nefrologia Pediátrica do Hospital UniversitárioJúlio Muller (HUJM), em Cuiabá, sendo que a seleção delas foi feita tomando-se em conta os seguintes critérios: famílias residentes na região da grande Cuiabá, cujo diagnóstico médico fosse $\mathrm{SN}$ em tratamento há pelo menos 12 meses; familiares dispostos a informar; familiares, com vivência e participação no processo de adoecer e no tratamento da criança. Participaram do estudo um total de 42 pessoas.

Para a coleta de dados, utilizamos: o histórico de enfermagem da família, a construção do genogramae do ecomapa, a análise de documentos (prontuários) e a entrevista em profundidade, aqui chamada de conversa.

A coleta de dados central e mais rica foi a conversa com as famílias. Usamos o termo "conversa” porque, diferentemente da palavra "entrevista", expressa melhoro sentido que desejamos imprimir a esta técnica de obtenção de dados: o diálogo. As conversas aconteceram nas casas das famílias ou no hospital, ora individualmente, ora com mais de um membro ou com toda a família. Após uma primeira interação, iniciávamos a conversa através de uma questão bem ampla, deixando claro o nosso interesse em conhecer como se dava a prática da 
família no cuidado à criança doente, enfatizando nosso desejo de compreendê-la em suas relações com todo o contexto no qual esta prática estava inserida. As conversas foram bem abertas, o que ofereceu flexibilidade, profundidade e interação com as pessoas.

Mergulhamos então no mundo empírico, no encontro com as famílias do estudo, nas suas vidas e nos seus discursos. Foi um encontro surpreendente no qual pesquisa e cuidado compartilhavam o mesmo momento espaço, uma experiência singular. Éramosa pesquisadora, mastambém a enfermeira envolvidacom o serviço ao qual as famílias se vinculavam em função do cuidado às crianças com problemas renais. Dilemas de toda ordem foram vividos: éticos, profissionais e pessoais. Enquanto pesquisadora, com freqüência nos enxergávamos como enfermeira ou como pessoa comum - como mulher, mãe, filha, cidadã. Muitas vezes, os mundos daquelas famílias apresentavam interfaces que nos levavam a analisar nossa própria família. Diversos problemas suscitados nas famílias nos remetiam às relações nas quais estávamos envolvidas dentro de nossa família, em nosso mundo privado, dilemas que não seriam tão perceptíveis não estivéssemos imersas em reflexões sobre o cuidado e a família.

Com os dados coletados, nos debruçamos sobre eles e enxergamos inúmeras possibilidades de diálogo com as famílias, a ponto de percebermos que o próprio cuidado poderia ser encarado como um diálogo. $\mathrm{O}$ processo de análise, ou melhor, de compreensão dos dados foi sistematizado, sendo que todas as fases foram enriquecidas durante o seu desenvolvimento.

Para o registro e organização dos dados elaboramos nosso diário de campo com um cabeçalho onde constavam os dados de identificação da pesquisa e da família e um corpo com três colunas denominadas seqüencialmente de: 1) "texto bruto", 2) "pré-categorização dos textos" e 3) "categorização dos textos".

Na primeira coluna - "texto bruto" - os diálogos foram transcritos na íntegra, tanto as perguntas quanto as respostas e também algumas reflexões pessoais que fazíamos após cada encontro. Somente depois de transcritas todos as conversas - o que representou uma forma de distanciamento dos textos - foi que retomamos a sua leitura. Procedemos, então, a uma leitura repetida do material como um exercício para alcançar os sentidos e significados fundamentais dos textos como um todo, uma vez que o sentido do todo influenciaria a discussão dos distintos temas (as partes) que emergiram da categorização dos dados. Assim, o primeiro encontro com o texto foi influenciado por uma percepção de "antecipação", a qual já estava desenvolvida em nós, como pesquisadora, através da tradição e dos nossos preconceitos e prejuízos.

$\mathrm{Na}$ fase seguinte, extraímos do "texto bruto" aqueles trechos significativos, dando a eles um título provisório a partir de nossa primeira impressão sobre eles (interpretação ingênua). Estes trechos "pré-categorizados" foram copiados e inseridos na segunda coluna do diário e foram analisados de modo a exporem seus significados para a compreensão do assunto. Este estágio facilitou a identificação de temas, os quais, por sua vez, conduziram a uma mais rica e detalhada compreensão do fenômeno sob investigação, ou seja, o cuidado. Estes temas, porsuavez, provocarameentraramemconfronto com nossos preconceitos enquanto pesquisadora.

Os trechos pré-categorizados foram reagrupados segundo suas semelhanças ou relação próxima na terceira coluna do diário - "categorização dos textos”. Este agrupamento dos dados em categorias nos parecia que, em certa medida, prejudicava a visão do todo, uma vez que fragmentava o texto. Por outro lado, foi a partir da fragmentação do texto em pré-categorias que pudemos organizar os capítulos de análise segundo os temas que se destacavam dos dados. A pergunta que se impôs: como organizar o texto de tal modo que ele não perca o seu sentido? Como organizá-lo de modo que o leitor consiga ter um visão ampla do contexto da família, penetrar no seu mundo e compreendê-las no seu movimento para o cuidado das suas crianças doentes?

Cada um dos trechos foi, então, relacionado ao todo, e, com isso, o sentido foi ampliado. Neste momento, nossaintenção foi de fazero exercício do círculo hermenêutico, ${ }^{12}$ essencial para o alcance da compreensão. O círculo hermenêutico somente é experienciado completamente se o movimento de volta para o todo estiver incluído na pesquisa apoiada na filosofia hermenêutica. Com a expansão da compreensão para o todo do texto, o sentido das partes pôde ampliar-se também, identificando os aspectos que pareciam representativos para a compreensão e que foram compartilhados entre pesquisadora e participantes. Certamente, temas surgidos dos dados, também levarão o leitor a reflexões sobre o fenômeno que estamos apresentando.

Pensando em preservar o sentido do todo, consideramos importante que o primeiro capítulo da discussão fosse a apresentação das famílias participantes do estudo de modo que os seus projetos, seus personagens e o contexto no qual estes estavam inseridos fossem compreendidos. Fizemos isso a partir da leitura global das entrevistas de cada família, extraindo os aspectos maisimportantes paraasuacaracterização. Parafacilitar a compreensão das relações entre os seus membros e o 
contexto para o cuidado, construímos o genograma e o ecomapa de cada família e analisamos brevemente cada uma delas. Ao final deste capítulo, fazemos uma síntese das famílias, mostrando o que elas têm em comum e também as suas singularidades.

Como em qualquer pesquisa, o pesquisador que segue uma abordagem hermenêutica deve demonstrar critérios de confiança. Nesta investigação, a confiança pode ser demonstrada pela documentação das várias decisões tomadas durante o processo de pesquisa. $\mathrm{O}$ uso de citações diretas dos textos demonstra que as perspectivas dos sujeitos da pesquisa foram representadas o mais claramente possível e podem auxiliar o leitor a fazer um julgamento quanto à credibilidade $\mathrm{e}$ confiabilidade dos dados. A objetividade na pesquisa hermenêutica pode ser entendida pela fidelidade em apresentar os textos. Contudo, este é um ideal que não pode ser alcançado inteiramente, uma vez que os leitores interpretarão os achados da pesquisa a partir de seus próprios horizontes. Neste aspecto, a confiança no processo da pesquisa e a "verdade" da compreensão caminham lado a lado. Não há verdade que seja universal porque nenhuma afirmação pode escapar da complexidade dainterpretação. ${ }^{12}$ Assim, a compreensão somente pode ser alcançada pela harmonia do todo e das partes do texto. Isto oferece um parâmetro de confiança melhor em relação ao processo do que simplesmente as conclusões da pesquisa. Daí nossa responsabilidade e cuidado, como pesquisador hermenêuta, em oferecer os detalhes de todo o processo.

Durante todo o processo de trabalho de campo, obedecemos rigorosamente às normas oficiais vigentes para a realização de pesquisa envolvendo seres humanos através da Resolução do Conselho Nacional de Saúde No $196 / 96 .{ }^{15}$ O projeto da pesquisa foi aprovado pelo Comitê de Ética em Pesquisa do Hospital Universitário onde foi realizada a coleta de dados (protocolo 131/CEP-HUJM/2003).

\section{RESULTADOS}

As famílias estudadas têm em comum histórias de perdas, afastamento das origens, morte de pessoas significativas, separações, paternidades presumidas e outros problemas de saúde além da doença da criança em foco.

Elas não são famílias "convencionais" e têm uma grande mobilidade no espaço. São famílias que vão se compondo e se recompondo a partir de diversas lógicas, sejam laços afetivos, seja pela responsabilidade determinada pelo parentesco ou ainda pela compaixão. As condições materiais de existência são sofríveis, permeadas por histórias de exploração de homens e mulheres em trabalhos árduos, insalubres ou mal remunerados.

Elas trazem fatos que aparentemente não têm nenhuma relação com o cuidado da criança doente. Isso nos leva à supor que as famílias julgam ser necessário, primeiramente, darem-se a conhecer através de suas histórias para que compreendamos o contexto no qual o cuidado ocorre.

Apesar de todo o sofrimento, as famílias mostram-se satisfeitas em contar as suas histórias. Nesse sentido, parece haver uma hierarquia no pensamento, uma conexão que as levam a contar sua experiência no cuidado à criança desde o seu início - primeiro como família - seguindo uma cronologia. Como se os "porta-vozes" das famílias tivessem pensado apoiados na seguinte lógica: ela (a pesquisadora) precisa saber primeiro como é a minha família.

A trajetória da doença crônica da criançaé relatada pelas pessoas da família, não como um episódio, mas como uma aventura repleta de detalhes e de incertezas. Elas contam minúcias sobre o caminho percorrido desde o início da doença e buscam explicações ou relações causais para a sua ocorrência. Contam sobre as mudanças ocorridas na vida da família a partir do aparecimento da doença, sendo que muitas vezes estas acontecem de modo radical. São alterações que se dão nos comportamentos, sentimentos dos seus membros, nas rotinas familiares, na vida social ou na vida escolar, até mesmo mudanças relacionadas à cidade, ao trabalho dos pais e ao modo de ver a vida. A trajetória da doença aparece nos relatos das famílias sempre acompanhada por depoimentos emocionados sobre o percurso que fizeram para alcançar o tratamento que consideram adequado, o esforço que fazem para superar as dificuldades financeiras em razão da manutenção do tratamento, o temor das recidivas e também o orgulho da família em superar o pior.

As falas deixam transparecer claramente que a chegada ao Serviço de Nefrologia Pediátrica doHUJM representa um marco importante neste caminho, delimitando dois períodos distintos, ou seja, o "antes" e o "depois do Júlio Müller".

A trajetória contada pelasfamílias mostraqueelas não se submetem totalmente à determinadas terapêuticas, serviços ou profissionais quando não percebem uma resolutividade conveniente ou compatível com as suas crenças. Não se submetem enquanto não se convencem de que determinadas intervenções sejam realmente confiáveis ou necessárias. 
Mesmo que as pessoas não tenham um profundo conhecimento sobre a doença e sobre a própria saúde, elas sempre trazem uma noção do que seja bom ou do que seja ruim para si. Em outros termos, as pessoas têm capacidade de julgamento e, através de seus relatos, percebemos que as famílias são capazes de preservar a vida dos indivíduos sob os seus cuidados, primeiramente, através do saber prático, da prudência e da ponderação. O sentido de "saber prático" aqui utilizado nos remete ao conceito de phronesis elaborado primeiramente por Aristóteles. ${ }^{12}$ "No conceito de phronesis está não apenas o sentido prático para atender determinados fins, mas também a capacidade de determinar esses fins e responsabilidades por eles. Há o reconhecimento da situação concreta da vida e o que é passível de ser feito, baseado no sensus communis. O senso comum é a "[...] capacidade universal que existe em todos os homens [...], o que dá à vontade humana a sua diretriz [...]". ${ }^{12: 27}$ No cotidiano, é o conhecimento que guia, que orienta e que dá sentido às decisões. As famílias são as responsáveis pelo cuidado e elas o administram através do bom senso.

Deste modo, elas se movimentam em várias direções na busca dos recursos de saúde disponíveis, procuram o que julgam ser o melhor tratamento, o melhor procedimento ou o melhor terapeuta. Sempre com muitas dúvidas, em determinados momentos elas os aceitam, em outros os negam ou os escolhem.

É claro que, em muitas situações, as famílias não têm muitas opções e acabam por serem submetidas a um único serviço que conseguem ter acesso.

Contudo, todo este processo é acompanhado por grande sofrimento gerado pela necessidade de decidir o que fazer e pela situação objetiva: a criança doente.

\section{CONSIDERAÇÕES FINAIS}

Retomamos nossa pergunta de pesquisa: as crianças com SN estão sendo cuidadas? Como estão sendo cuidadas?

Concluímos que o diálogo é a primeira condição para a compreensão e também para o cuidado. A postura hermenêutica permitiu a nossa abertura para o diálogo com as famílias cuidadoras, sem a qual não seria possível a compreensão dos seus contextos, bem como dos seus horizontes e de seus olhares para o cuidado.

O encontro com as famílias foi um exercício de conversação na medida em que, como pesquisadoras e também enfermeiras, não podíamos, parafraseando Gadamer" "passar ao largo" dos familiares neste diálogo. Tínhamos em mente a primeira condição da arte de conversação, ou seja, nos assegurávamos de que os interlocutores, as pessoas das famílias, estivessem nos acompanhando no mesmo passo.

No diálogo com as famílias e também com os membros da equipe, diversos conceitos e opiniões foram elaborados, sempre com nosso esforço de não reprimir o outro com argumentos, mas, ao contrário, balancear as diferentes visões ou racionalidades. Considerando que as pessoas estavam cientes de nosso tema, ou seja, a compreensão de como as crianças com SN estão sendo cuidadas, o diálogo foi conduzido como a arte do ir experimentando. A arte de ir experimentando é a arte de perguntar. ${ }^{12}$ Todavia, perguntar quer dizer colocar aberto e por em suspenso o assunto com as suas possibilidades. ${ }^{12}$

Neste exercício de perguntas e respostas, de idas e vindas, os sujeitos falaram sobre as suas percepções de saúde e de doença e, também, as reelaboraram a partir do diálogo. Os familiares trouxeram à tona a discussão do sentimento de responsabilidade para a manutenção da saúde e da vida de suas crianças, entremeada por temas como o altruísmo, a superação do próprio sofrimento e o assumir perdas. O diálogo permitiu revelar quem são os cuidadores das crianças - mães, avós, tias, madrinhas, a própria criança - e o cuidado possível a partir do que a família dá conta, dos seus arranjos, da solidariedade da família estendida e da compaixão de outrem. As pessoas da equipe de saúde expuseram seus horizontes, seus dilemas e limites no enfrentamento do cuidado à criança e na abordagem da família. Mas todos os participantes do estudo, a partir do seu horizonte, enxergaram a necessidade de que cada uma das partes envolvidas nesse processo - criança, família, pesquisadora, equipe e serviços de saúde - interajam e se somem para compor o produto do amplo diálogo, ou seja, o cuidado.

\section{REFERÊNCIAS}

1 Nascimento LC. A Enfermagem da família na assistência à criança com câncer [tese]. Ribeirão Preto (SP): EERP/ USP; 2003.

2 Bergstein JM. Síndrome nefrótica. In: Behrman RE, KliegmanRM,JensonHB.TratadodePediatria.16aed.Rio de Janeiro (RJ): Guanabara Koogan; 2002. p.1568-72.

3 Kirsztajn GM, coordenador. Diretrizes brasileiras de glomerulopatias em adultos. São Paulo (SP): Sociedade Brasileira de Nefrologia; 2003. 
4 Sociedade Brasileira de Nefrologia. Apresenta o censo brasileiro de nefrologia de 2002 [acesso em 2003 Ago 20]. Disponível em: http://www.sbn.org. $\mathrm{br} /$ Censo/censo02.htm

5 Noronha IL, Schor N, Coelho SN, Jorgetti V, Romão Jr JE, Zatz R. Nephrology, dialysis and transplantation in Brazil. Nephrol. Dial. Transpl. 1997 Nov; 12 (11): 2234-43.

6 Lessa I. Outras doenças crônicas não transmissíveis. In: Lessa I. $\mathrm{O}$ adulto brasileiro e as doenças da modernidade. São Paulo (SP): Hucitec; 1998. p.181-201.

7 Freitas ACM. Da nefrose à corticodependência: um estudo da doença através das falas das mães [dissertação]. Ribeirão Preto (SP): USP/Faculdade de Medicina; 1997.

8 Mello SFR, Rego-Filho EA, Carlesso DRD. Síndrome nefrótica: opiniões e expectativas dos pacientes e seus pais. Jor. Paranaense Pediatria. 2003 Dez; 4 (4): 170-6.

9 Silva DMGV. Editorial. Texto Contexto Enferm. 2004 Jan-Mar; 13 (1): 11.
10 Knafl KA, Gillis CL. Families and chronic illness: a synthesis of current research.. Jour. Family Nursing. 2002 Ago; 8 (3): 178-98.

11 Vieira MA, Lima RAG. Crianças e adolescentes com doença crônica: convivendo com mudanças. Rev. Latinoam. Enferm. 2002 Jul-Ago; 10(4): 552-60.

12 Gadamer HG. Verdade e método: traços fundamentais de uma hermenêutica filosófica. $4^{a}$ ed. Petrópolis(SP): Vozes; 1997.

13 Ricouer P. Teoria da interpretação. Lisboa (PT): Edições 70; 1987.

14 Ayres JRCM. Hermenêutica e humanização das práticas de saúde. Ciência Saúde Coletiva. 2005 Jul-Set; 10 (3): 549-60.

15 Ministério da Saúde (BR), Conselho Nacional de Saúde, Comitê Nacional de Ética em Pesquisa em Seres Humanos. Resolução N. 196 de 10 de outubro de 1996: diretrizes e normas regulamentadoras de pesquisas envolvendo seres humanos. Brasília (DF): O Conselho; 1996. 